\title{
Can Video Motivate Students in Learning English During New Normal Era?
}

\author{
Widya Syafitri \\ IAIN Bukittinggi \\ email: widyasyafitri260780@gmail.com
}

\begin{abstract}
This study was aimed at investigating the effectiveness of the usage of video whether it can motivate students in learning English during new normal era. Educational process, nowadays, can't be disconnected with technology utilization. Covid-19 has forced the educators to implement technology in teaching process, as government demanded them to conduct blended learning before. In this situation, the students and educators meet some challenges. Feeling of isolated, one of challenges appears in students' mind. Thus, educators need to find the solution for it. This study was quantitative research method which had 20 students of second semester in Islamic banking as sample. The data collected through distributing questionnaires for pre-treatment and post-treatment. Analyzing results showed that using video in English learning during online class in new normal era was able to motivate students to learn.
\end{abstract}

Keywords: Video, New normal era, Covid-19, Motivation

\section{Introduction}

English has been a global language for communication. English is dominant language used in the world (British council, 2013). It is used in all aspects of life: politic, entertainment, business, science, technology, education, and many other fields of life. That is why English become a compulsory subject from elementary, for private school until higher education. Moreover, to prepare facing $21^{\text {st }}$ century, government has shifted to relevant curriculum which engages technology in it.

Nowadays education can't be separated with the use of technology. The rapid development of technology has influenced education curriculum, one of examples is implementing blended learning (hybrid education). Oxford Dictionary describes Blended Learning becomes an approach of education that students learn through online media and face-to-face studying. In this case, technology plays an important role. Hybrid instruction applies connected technology not only as complement, nevertheless convert also expand learning development. Related to Education Foundations, that advances hybrid learning technologies, effective hybrid learning happens once technology also education notify each other: instructional material nurture into energetic and they stimuli scholars of fluctuating education styles.

Government has prepared to succeed this blended or hybrid learning through many ways. Educational institutions hold several kinds of training for its practitioner. The teachers, lecturers are trained to be ready to conduct hybrid learning in their class. It is not a simple effort, since educators must be able to integrate technology in teaching. This fact, nowadays, benefits to students and other educators because of COVID-19 that forces hybrid or maybe fully online learning should be implemented.

COVID-19 expanding create compulsory lots of scholars also educators changing their educational practice in to connected communication. The educational institutions are locked till further announcement then the institutions need to adjust to a new education style of implementation. Educators and also 
administrators are thinking tough throughout lockdown trying to preserve students still enjoying education, everchanging to connected learning in short time. Though the advancement of technology growth nowadays tolerates many things, the movement to e-learning not yet drive as efficiently as we wish it to be. Fronting the drawbacks of e-learning may be unpromising and annoying both for educators and scholars.

As mentioned above, the educators and students will meet several virtual challenges during holding learning process. Some of them are: work processes organization and time management, Gadget's scarcity and roaring systems, Connectivity, Computer literacy, Data discretion, Isolation, Lack of interaction, LMS inadequacies, and many other challenges (Plitnichenko, 2020). Those effects influence students' motivation in learning included English lesson. One of the reasons is the educators and students have not mastered the utilizing of technology in education.

Concerning the isolation challenging, Plitnichenko said that it somewhat psychological aspect which is tranquil highly upsetting scholars' impetus and also learning development. In the classroom, scholars are accustomed to deed eye-to-eye communication among them. It allows responding, shading information, playful, \& assembly a non-verbal interaction, establish the social competence. For numerous scholars, a schoolroom become a kind of reservation, that is nowadays taken away. That's not a wonder lot of them sense lonely, frightened by the covid-19 pandemic, siblings' occupation loss, colleagues' discontinuation.

These problems also occur to students of IAIN Bukittinggi, since some of them live in remote area. Connectivity and economy because of parents' job loss become their new problems in following online class. Until now, it is hard for educators to conduct online class through zoom application in all meetings. Less than half of students could participate in learning process. To overcome this problem, researcher wanted to use video in teaching activity. The videos were produced by teacher using movie maker. Those kinds of video were uploaded to LMS, google classroom.

The teachers are demanded to improve themselves as inventor, creating video in achieving their scholars' desires while learning process. Through exhaustive usage of videos, the scholars may request somewhat which more exciting than the thing that only formed by somebody else. Many educators must know how to empower the scholars' desires and also generate real videos which can sustenance the scholars' learning process effectively. When the educators only organize many videos, they collected from cyber space or accepted in supplies, they are perhaps not fresh from the oven any longer for their scholars. They supposed they have watched the audiovisual, therefore it possibly will not be really working for some scholars. The educators are obliged toward progressing their inspiration in producing more appropriate videos intended for the scholars. Thus, this study was aimed at examining the use of video in motivating students in online English class.

\section{Utilizing Video in English Language Online Classroom}

Wang in 2015, described several purposes of teaching foreign language through video instructional materials. At first is enabling the progress of EFL students' language competence. That can be said, the video is able to deliver much information to the students, have courtesy in highlighting the material on video, and expand their wide-ranging linguistic proficiency. The next purpose is to promote scholars' capability of intercultural communication. If the video is obtainable on Google classroom, it is not only about giving information related to linguistic, but the scholars also can acquire around culture of English of native speakers. The third purpose, it can sustenance the students' communicative proficiency in English. Since video produced by teacher, its material can contain about local culture. Then to encourage learners' visual values also aptitude to escalate English videos of Imaginative values. Therefore, the video does not only extant material concerning everything the students already watched, but also, it's estimated to have the scholars own aesthetic parodies of the video to their awareness. It must be able to inspire them to own deeper thinking and also critical review. Thus, the scholars can fasten much profits from the video material. 


\section{Methods}

This research used two motivation questionnaires to the students. It covers 20 items questions of Likert-scale including two sub-categories: The first, positive attitudes to studying English, and the rest is negative attitudes about studying English. Though quantitative research method implementation to examine language learners' motivation has become disparaged on a number of counts (Dörnyei, 2001; Kim, 2005, 2006), the questionnaire reviews were directed to increase a simple comprehension of the relation among a precise instructional technique and motivation. Researcher desired to investigate about how the students' motivational attitude improved afterward they acquired the class. Assessing motivational alteration become significant to us as our whole exertion was constructed on the belief that offering video materials to EFL higher education will effect to be a positive transformation in their attitude about English.

\section{Result and Discussion}

The following table 1 showed result of learning motivation before and after treatment implemented to second semester students of Islamic Banking in IAIN Bukittinggi, especially in class C. There were significant improvements when compared between two results of distributing questionnaires.

Table 1. Learning Motivation Achievement

\begin{tabular}{|c|c|c|c|}
\hline \multirow[t]{2}{*}{ No } & \multirow[t]{2}{*}{ Name } & \multicolumn{2}{|c|}{ Learning Motivation } \\
\hline & & $\begin{array}{c}\text { Pra- } \\
\text { Treatment }\end{array}$ & $\begin{array}{c}\text { Post- } \\
\text { Treatment }\end{array}$ \\
\hline 2 & SA & 106 & 168 \\
\hline 3 & DA & 99 & 186 \\
\hline 4 & MR & 101 & 185 \\
\hline 5 & NA & 106 & 156 \\
\hline 6 & SL & 104 & 162 \\
\hline 7 & $\mathrm{FH}$ & 108 & 145 \\
\hline 8 & LF & 105 & 203 \\
\hline 9 & SR & 109 & 202 \\
\hline 10 & RK & 110 & 205 \\
\hline 11 & AUP & 106 & 141 \\
\hline 12 & FA & 106 & 177 \\
\hline 13 & ELS & 110 & 159 \\
\hline 14 & EHP & 107 & 205 \\
\hline 15 & RWS & 95 & 115 \\
\hline 16 & SK & 105 & 141 \\
\hline 17 & WS & 110 & 195 \\
\hline 18 & DAP & 87 & 162 \\
\hline 19 & AS & 98 & 138 \\
\hline 20 & WARS & 100 & 175 \\
\hline & Mean & 103,55 & 166,65 \\
\hline
\end{tabular}

Language Learning Innovation in Pandemic Covid-19 Era 
The data were analyzed using the Wilcoxon test which was processed by SPSS 21 . There were only 20 research samples, so the researchers analyzed the data using the Wilcoxon test. It means it is no need to examine normality distribution and to find homogeneity. The following are the results of data analysis of the results of data processing before and after getting treatment with learning English using video, as well as its effect on students' motivation to learn English.

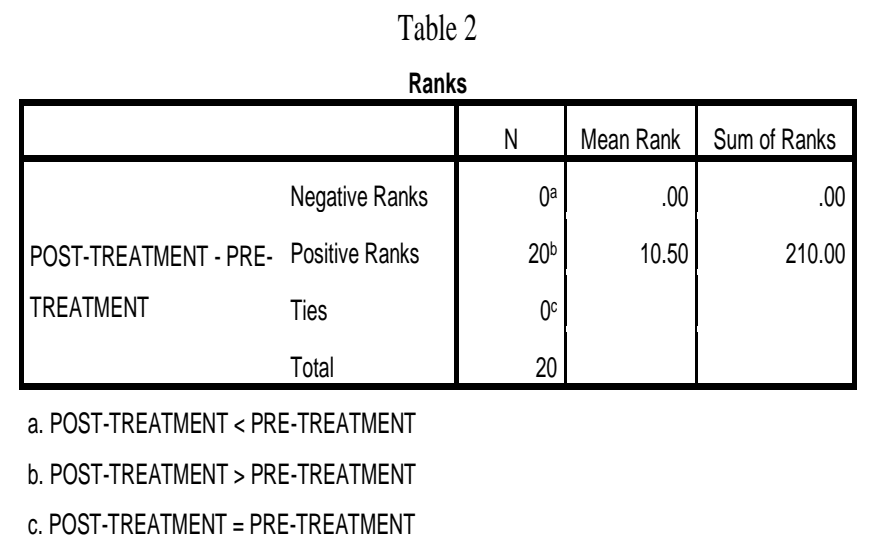

Negative Ranks or the difference (negative) between motivation to learn English for before treatment and after treatment is 0 , both in the value of N, Mean Rank and Sum of Rank. This 0 value indicates no decrease (reduction) from the value of learning motivation before to the value after receiving treatment.

Positive rank or difference (positive) between the results of learning English for pre-treatment and post-treatment. In here there are 20 positive data $(\mathrm{N})$, which means that the 20 students experienced increased in motivation to learn English since pre-test scores to post-treatment scores. The mean rank or average increase is 10.50 . Though the number of positive grades or sum of ranks is 210 .

Ties is the parallel of pre-treatment and post-treatment values, here the Ties value is empty, so it can be stated that there is no equal value among pre-treatment and post-treatment.

Table 3. Test Statistics ${ }^{\mathrm{a}}$

\begin{tabular}{lr}
\hline & \multicolumn{2}{c}{ Post-Treatment - } \\
& Pre-Treatment \\
$\mathrm{Z}$ & $-3.921^{\mathrm{b}}$ \\
Asymp. Sig. (2- & .000 \\
tailed) & \\
a. Wilcoxon Signed Ranks Test \\
b. Based on negative ranks. \\
\hline
\end{tabular}

The basis for decision making on the Wilcoxon test, if the value of Asymp.sig <0.05, then the hypothesis is acceptable. If the value of Asymp.sig > 0.05, then the hypothesis is declined. Decision making based on statistical test output is known that Asymp.sig ( 2 tailed) is worth 0.000 . Due to the value of 0.000 is lesser than 0.05 , it can be resolved that the hypothesis is accepted. This means that it is found a difference among the motivation to learn English before and after using video in learning English. So, it can be concluded that there is an effect of using video in studying English on students' learning motivation for second semester students of class $\mathrm{C}$ of Islamic Banking in IAIN Bukittinggi. 


\section{Conclusion}

Inclusively, this research has exposed that learning English by means of applying video is effective to cultivate students' motivation. To cover the preceding study question, the utilization of video for EFL higher education students seems to support improving students' motivation in learning English. This small-scale experimental study provides signal that integrating video instructional material into second language classrooms can be valuable for online English learning in IAIN Bukittinggi especially for second semester of Islamic banking students. The students found problems, like feeling isolated and connectivity during online learning. Thus, using video material can be one of solutions as variation but of course it is not the only type of media used during learning English in one semester for online class.

\section{Acknowledgments}

I dedicate this scientific writing and also my special respectful to beloved family; parents, husband, and my children. Thanks a bunch for all supports and affection.

\section{References}

British Council. (2013). The English Effect. https://www.britishcouncil.org/sites/default/files/englisheffect-report-v2.pdf.

Dörnyei, Z. (2001). Motivational strategies in the language classroom. Cambridge, UK: Cambridge University Press. http://dx.doi.org/10.1017/CBO9780511667343.

Dörnyei, Z. (2005). The psychology of the language learner: Individual differences in second language acquisition. Mahwah, NJ: Lawrence Erlbaum. http://dx.doi.org/10.1177/0261927X05281424.

Kim, T. Y. (2006). Motivation and attitudes toward foreign language learning as socio-politically mediated constructs: The case of Korean high school students. The Journal of Asia TEFL, 3(2), 165-192. http://dx.doi.org/10.1007/s12564-010-9071-7.

Kim, T. Y. (2005). Reconceptualizing L2 motivation theory: Vygotskian activity theory approach. English Teaching, 60(4), 299-322. http://dx.doi.org/10.15858/engtea.68.4.201312.141.

Plitnichenko, L. (2020). 10 challenges of e-learning during COVID-19. https://jellyfish.tech/10challenges-of-e-learning-during-covid-19/.

Wang, Z. (2015). An analysis on the use of video materials in College English Teaching in China. International Journal of English Language Teaching, 2(1). 